Article

\title{
Copolymerization of Phenylselenide-Substituted Maleimide with Styrene and Its Oxidative Elimination Behavior
}

\author{
Qian Liu, Xinghua Lv, Na Li, Xiangqiang Pan *, Jian Zhu *(1) and Xiulin Zhu \\ State and Local Joint Engineering Laboratory for Novel Functional Polymeric Materials, \\ Department of Polymer Science and Engineering, College of Chemistry, Chemical Engineering and Materials \\ Science, Soochow University, Suzhou 215123, China; qliu1@stu.suda.edu.cn (Q.L.); t_zhuj@suda.edu.cn (X.L.); \\ chemlina@suda.edu.cn (N.L.); xlzhu@suda.edu.cn (X.Z.) \\ * Correspondence: panxq@suda.edu.cn (X.P.); chemzhujian@suda.edu.cn (J.Z.); \\ Tel.: +86-512-6588-2752 (X.P. \& J.Z.)
}

Received: 9 February 2018; Accepted: 10 March 2018; Published: 15 March 2018

\begin{abstract}
Selenium-containing monomer monophenyl maleimide selenide (MSM) was synthesized and copolymerized with styrene (St) using reversible addition-fragmentation chain transfer (RAFT) polymerization. Copolymers with controlled molecular weight and narrow molecular weight distribution were obtained. The structure of the copolymer was characterized by nuclear magnetic resonance, matrix-assisted laser desorption/ionization time-of-flight (MALDI-TOF) mass spectrum, Fourier transform infrared spectroscopy (FT-IR) and Ultraviolet-visible spectroscopy (UV-vis) spectroscopy. The copolymer can be oxidized by $\mathrm{H}_{2} \mathrm{O}_{2}$ to form carbon-carbon double bonds within the main chain due to the unique sensitivity of selenide groups in the presence of oxidants. Such structure changing resulted in an interesting concentration-related photoluminescence emission enhancement.
\end{abstract}

Keywords: selenium-containing monomer; reversible addition-fragmentation chain transfer (RAFT); oxidation; carbon-carbon double bond

\section{Introduction}

The selenium containing group has been widely used as an antioxidant due to low binding energy of the selenium-carbon bond [1]. Many selenium-containing compounds are promising multi-responsive materials with unique redox properties [2]. Great efforts in material chemistry fields have been reported based on the redox property of selelnium-containing compounds [3-5]. $\mathrm{Xu}$ et al. reported a novel amphiphilic block copolymer with oxidation responsive selenide moieties which can undergo a disassembled in a mild oxidative environment and a reversible reduction upon the addition of Vitamin $C$ [6]. In addition, depending on the redox property of selenium-containing compounds, some selenium-containing probes for sensitive and selective detection of oxygen species were reported [7]. For example, Manjare et al. designed a diselenide-based boron dipyrromethene (BODIPY) probe for detecting superoxide [8]. After oxidation, the ability for the photo-induced electron transfer from the selenium to the fluorophore was removed and the probe gave a fluorescence response. In 2017, a dynamic hydrogel containing diselenide moiety was proposed by Pan et al. which showed redox and temperature responses by selectively oxidation of selenol-terminated chain. Through this method, such material could lead to the reconstruction of a hyperbranched architecture and a transition to gel state [9].

In fact, selenium-containing moieties could be eliminated at mild conditions. Yuki et al. demonstrated that selenide end functionalized polymer could be oxidized to the corresponding polymer with terminal selenoxide, and they followed this method by elimination to give a polymer 
containing a double bond at terminal groups [10]. In 2016, Dai et al. obtained highly regioselective carbonselenation styrene in the presence of $\mathrm{H}_{2} \mathrm{O}_{2}$ [11]. This reaction is an efficient method for the synthesis of target alkenes via selenoxide syn elimination and chiral hydrocarbons that bear an aryl moiety at the stereogenic carbon atom if a chiral selenium regent is used.

Dithiomaleimide is a new fluorescent small molecule demonstrated by Rachel K. O'Reilly et al. in 2013 [12]. Additionally, in 2015, the same group presented a library of amino-maleimides which showed an intense fluorescence emission in cases of maleimide with ankyl primary amines substitution [13]. Recently, using a stable Ru(II)-catalyst, Mahiuddin Baidya reported a series of seleno-substituted maleimides with excellent yield (up to 94\%) [14]. In 2016, Haddleton et al. synthesized a dithiomaleimide-containing monomer [15]. It was successfully copolymerized with poly(triethyene glycol methyl ether acrylate) to endow copolymers with thermos-responsive and fluorescent properties. Furthermore, polymers with multiple carbonyl $(\mathrm{C}=\mathrm{O})$ moieties can demonstrate strong photoluminescence (PL) emission under proper conditions $[16,17]$. These polymers showed poor PL emission in solution. However, in solids or viscous liquids, PL emission could be enhanced [18]. In 2017, Shiao-Wei Kuo et al. reported an interesting monomer, namely, 2-aminobutyl maleimide isobutyl polyhedral oligomeric silsesquioxane, which had a lack of conventional fluorescent groups [19]. After it copolymerized with maleimide-containing monomer, the copolymer displayed strong light emission due to the intermolecular hydrogen bonding between the amino and dihydrofuran-2,5-dione group and clustering of the locked $\mathrm{C}=\mathrm{O}$ groups.

Seleno-mediated radical polymerization (SeRP) has been widely used as a method applicable to get selenium-containing polymers [20,21]. However, there have been few reports about the radical polymerization of vinyl monomers containing selenide moiety. This was probably due to the strong interaction of selenium stom with free radicals [22,23]. In 1996, Yuki et al. reported a new type of selenium-containing vinyl monomers ( $p$-methylselenostyrene and $p$-phenylselenostyrene) which can polymerize with azodiisobutyronitrile (AIBN) or benzoyl peroxide (BPO) as initiator to afford the corresponding polymers [24]. In 2017, Pan et al. demonstrated a selenide-containing monomer to the preparation of dynamic covalent cross-linked polymers [25]. This monomer can simultaneously act as a comonomer, cross-linker, initiator and mediator.

Based on the literature survey, herein, we prepared a selenium-containing maleimide monomer monophenyl maleimide selenide (MSM) which could copolymerize with styrene by reversible addition-fragmentation chain transfer (RAFT) polymerization (Scheme 1a). Copolymers with controlled molecular weight distribution were successfully obtained. Furthermore, due to the cleaving of weak selenium-carbon bond, the molecular of copolymer was decreased when treated with $\mathrm{H}_{2} \mathrm{O}_{2}$ and then carbon-carbon double bonds were formed in the backbone of oxidized copolymer (Scheme 1b). This procedure provides a new candidate for preparing cross-linked polymer using the internal carbon-carbon double bonds as cross-linker. Besides, for the oxidized copolymer, the PL emission intensity of spectral region at $460 \mathrm{~nm}$ could be enhanced both in solid state and in solution.

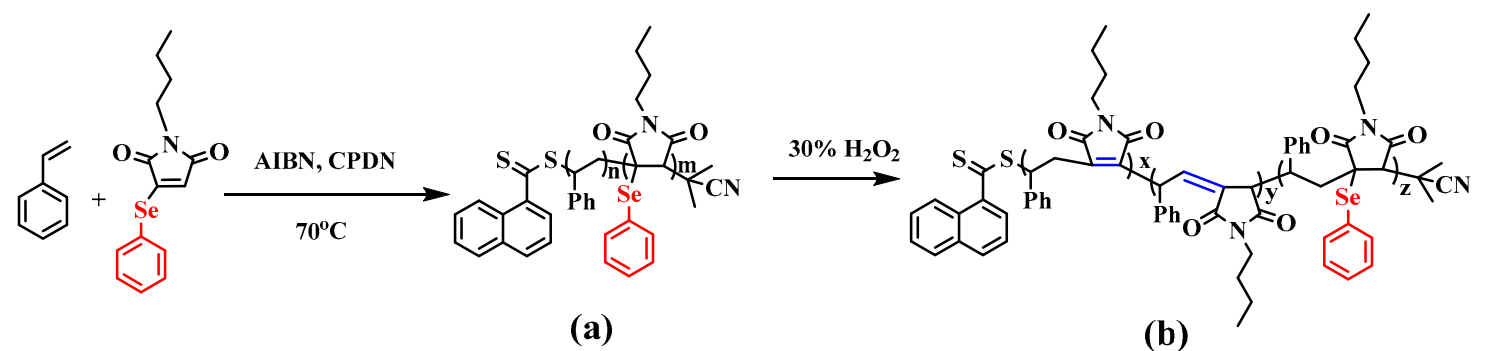

$$
\mathbf{x}+\mathbf{y}+\mathbf{z}=(\mathbf{m}+\mathbf{n}) / 2
$$

Scheme 1. Synthetic route of copolymer (a) and its corresponding oxidative structure (b). 


\section{Materials and Characterization}

\subsection{Materials}

Styrene (St, Sinopharm Chemical Reagent, Shanghai, China, 99\%) was purified by passing through a short $\mathrm{Al}_{2} \mathrm{O}_{3}$ columns before use. Diphenyl diselenide (DPDS) [26], 2-cyanoprop-2-yl1-dithionaphthalate (CPDN) $[27,28]$ and $N$-butyl-monobromomaleimide [29] were synthesized according to literature procedures. 2,2-Azobisisobutyronitrile (AIBN, Sinopharm Chemical Reagent, China, 98\%) was purified by recrystallization from ethanol. Other reagents were purchased from Sinopharm Chemical Reagent Co., Ltd. and were used without further purification.

\subsection{Characterization}

The number-average molecular weight $\left(M_{n}\right)$ and molecular weight distribution $(\nexists)$ of the polymers were determined by a TOSOH HLC-8320 gel permeation chromatograph (GPC) equipped with a refractive index and UV detector (Tosoh Bioscience Shanghai Co. Ltd., Shanghai, China), using two TSK gel super 20 Multipore HZ-N $(4.6 \times 150 \mathrm{~mm}, 3 \mu \mathrm{m}$ beads size $)$ with measurable molecular weights ranging from 500 to $1.9 \times 10^{5} \mathrm{~g} / \mathrm{moL}$. Tetrahydrofuran (THF) was used as the eluent at a flow rate of $0.35 \mathrm{~mL} / \mathrm{min}$ at $40{ }^{\circ} \mathrm{C}$. Data acquisition was performed using EcoSEC software (Tosoh Bioscience Shanghai Co. Ltd., Shanghai, China). The ${ }^{1} \mathrm{H}$ NMR and ${ }^{13} \mathrm{C}$ NMR spectra were recorded on a Bruker $300 \mathrm{MHz}$ nuclear magnetic resonance instrument (Bruker Daltonics Inc., Billerica, MA, USA) using $\mathrm{CDCl}_{3}$ as the solvent and tetramethylsilane (TMS) as the internal standard. The ${ }^{77}$ Se NMR was recorded on a Bruker $600 \mathrm{MHz}$ nuclear magnetic resonance (Bruker Daltonics Inc., Billerica, MA, USA) instrument using $\mathrm{CDCl}_{3}$ as the solvent and tetramethylsilane (TMS) as the internal standard. Matrix-assisted laser desorption/ionization time-of-flight (MALDI-TOF) mass spectroscopy were acquired on an UltrafleXtreme MALDI TOF mass spectrometer (Bruker Daltonics Inc., Billerica, MA, USA) equipped with a $150 \mathrm{kHz}$ smart beam-II laser. FT-IR spectra were obtained on a BrukerTENSOR-27 FT-IR spectrometer (Bruker Daltonics Inc., Billerica, MA, USA) by mixing the polymer with $\mathrm{KBr}$ as tablets. The UV-vis spectra were recorded on a Shimadzu UV-3150 spectrophotometer at room temperature (Shimadzu China, Shanghai, China). The photoluminescence (PL) spectra of the samples were determined with a Hitachi F-4600 fluorescence spectrophotometer (Hitachi (China) Ltd., Shanghai, China) using a monochromated Xe lamp as an excitation source with a scanning rate of $1200 \mathrm{~nm} \mathrm{~min}{ }^{-1}$. The excitation and emission slits were both set at $5 \mathrm{~nm}$. Differential scanning calorimetry (DSC) was performed with heating and cooling rates of $10^{\circ} \mathrm{C} / \mathrm{min}$ on a PerkinElmer Diamond DSC instrument (PerkinElmer, Billerica, MA, USA) equipped with a cooling system under continuous nitrogen flow. Thermogravimetric analysis (TGA) was performed on a 2960 SDT TA instruments with a heating rate of $10^{\circ} \mathrm{C} / \mathrm{min}$ from room temperature to $800{ }^{\circ} \mathrm{C}$ under a nitrogen atmosphere.

\subsection{Synthesis of Monoselenomaleimide (MSM)}

To a solution of DPDS (1.56 g, $5 \mathrm{mmol}$ ) in $50 \mathrm{~mL} \mathrm{C} \mathrm{C}_{2} \mathrm{H}_{5} \mathrm{OH}-\mathrm{DMF}$ (3:2) was added $\mathrm{NaBH}_{4}$ $(0.15 \mathrm{~g}, 4 \mathrm{mmol})$ under nitrogen atmosphere at room temperature. After $30 \mathrm{~min}$ of stirring, $\mathrm{N}$-butyl-monobromomaleimide $(1.16 \mathrm{~g}, 5 \mathrm{mmol})$ was added at $0{ }^{\circ} \mathrm{C}$. The solution was stirred for $30 \mathrm{~min}$. The reaction mixture was extracted with dichloromethane $(3 \times 40 \mathrm{~mL})$ and washed with water. The organic layer was dried over anhydrous magnesium sulfate and concentrated. The residue was subjected to column chromatographic separation (Silica gel, [Hexane] $/[$ Ethyl acetate] $=20 / 1, v / v$ ) to give $0.81 \mathrm{~g}$ (66\% yield) of monophenyl maleimide selenide (MSM). ${ }^{1} \mathrm{H} \mathrm{NMR}\left(300 \mathrm{MHz}, \mathrm{CDCl}_{3}, \delta, \mathrm{ppm}\right)$ (Figure S1): 7.66-7.64 (m, 1H), 7.63-7.61 (m, 1H), 7.50-7.38 (m, 3H), $5.86(\mathrm{~s}, 1 \mathrm{H}), 3.51(\mathrm{t}, J=7.2 \mathrm{~Hz}, 2 \mathrm{H})$, $1.63-1.50(\mathrm{~m}, 2 \mathrm{H}), 1.31(\mathrm{~m}, 2 \mathrm{H}), 0.92(\mathrm{t}, J=7.3 \mathrm{~Hz}, 3 \mathrm{H}) .{ }^{13} \mathrm{C} \mathrm{NMR}\left(75 \mathrm{MHz}, \mathrm{CDCl}_{3}, \delta, \mathrm{ppm}\right)$ (Figure $\left.\mathrm{S} 2\right)$ : $\delta=169.76$ (1C), $169.01(1 \mathrm{C}), 150.22$ (1C), 135.88 (2C), 130.26 (2C), 130.04 (1C), 125.48 (1C), $123.90(1 \mathrm{C})$, 38.01 (1C), 30.63 (1C), 19.96 (1C), 13.55 (1C). ${ }^{77} \mathrm{Se} \mathrm{NMR}\left(600 \mathrm{MHz}, \mathrm{CDCl}_{3}, \delta, \mathrm{ppm}\right)$ (Figure S3): $\delta=387.51(1 \mathrm{Se})$. 


\subsection{General Procedures for Reversible Addition-Fragmentation Chain Transfer (RAFT) Polymerization of Styrene and MSM}

The polymerization was carried out in a baked Schlenk tube under argon protection. As for the molar ratio with $[\mathrm{St}]_{0} /[\mathrm{MSM}]_{0} /[\mathrm{CPDN}]_{0} /[\mathrm{AIBN}]_{0}=200 / 200 / 2 / 1, \mathrm{MSM}(2.67 \mathrm{~g}, 8.62 \mathrm{mmol})$, St $(1.0 \mathrm{~mL}, 8.63 \mathrm{mmol})$, CPDN (23.3 mg, $0.086 \mathrm{mmol})$ and AIBN $(7.1 \mathrm{mg}, 0.043 \mathrm{mmol})$ were added into the tube. Toluene $(50 \mu \mathrm{L})$ was added and used as internal standard for ${ }^{1} \mathrm{H}$ NMR calculation. A small portion of the mixture was collected for the determination of the initial monomer ratio by ${ }^{1} \mathrm{H}$ NMR. The solution was degassed through a freeze-pump-thaw three times. Then, the reaction tube was bathed in an oil bath preset at $70{ }^{\circ} \mathrm{C}$. Monomer conversion was determined by ${ }^{1} \mathrm{H}$ NMR spectroscopy. After the predetermined time, a portion of the polymerization mixture was directly dissolved in $\mathrm{CDCl}_{3}$ for ${ }^{1} \mathrm{H}$ NMR analysis to determine the respective monomer conversion. In the whole process of polymerization, the contents of toluene did not change, so the integral of toluene in the ${ }^{1} \mathrm{H}$ NMR could be easily used as an internal standard for evaluating the conversion of monomers by comparing the integral value of double bonds with that of toluene. The typical spectrum is shown in Figure S4. The residual mixture was dissolved in THF and precipitated in an excess of methanol. After filtration, the copolymer was dried in vacuum at $30{ }^{\circ} \mathrm{C}$ for $24 \mathrm{~h}$.

\subsection{Oxidation of Copolymer Using $\mathrm{H}_{2} \mathrm{O}_{2}$ as Oxidizing Agent}

The oxidation was carried out in a $2 \mathrm{~mL}$ ampoule with copolymer $(35 \mathrm{mg}$, sample in Table 1 Entry 4) in THF ( $1 \mathrm{~mL})$ and oxidized with $\mathrm{H}_{2} \mathrm{O}_{2}(45 \mu \mathrm{L}, 30 \% v / v)$ at room temperature for $3 \mathrm{~h}$. Subsequently, the solution was precipitated in methanol. After filtration, the copolymer was dried in vacuum at $30{ }^{\circ} \mathrm{C}$ for $24 \mathrm{~h}$.

Table 1. Reversible addition-fragmentation chain transfer (RAFT) polymerization of St and monoselenomaleimide (MSM) under different molar ratios ${ }^{\text {a }}$.

\begin{tabular}{|c|c|c|c|c|c|c|}
\hline Entry & {$[\mathrm{St}]_{0} /[\mathrm{MSM}]_{0} /[\mathrm{CPDN}]_{0} /[\mathrm{AIBN}]_{0}$} & Time (h) & Conv.St ${ }^{b}(\%)$ & Conv.MSM $^{\mathrm{b}}(\%)$ & $M_{\mathrm{n}}^{\mathrm{c}}(\mathrm{g} / \mathrm{mol})$ & $\boxplus^{\mathrm{c}}$ \\
\hline 1 & $200 / 6 / 2 / 1$ & 2.0 & 20 & 100 & 2000 & 1.28 \\
\hline 2 & $200 / 20 / 2 / 1$ & 2.5 & 51 & 100 & 2600 & 1.35 \\
\hline 3 & $200 / 60 / 2 / 1$ & 10 & 27 & 25 & 2500 & 1.43 \\
\hline 4 & $200 / 200 / 2 / 1$ & 9.0 & 34 & 27 & 3100 & 1.62 \\
\hline 5 & $0 / 200 / 2 / 1$ & 24.0 & N.A. & - & - & - \\
\hline
\end{tabular}

Polymerization conditions: ${ }^{\mathrm{a}} V_{\mathrm{St}}=1.0 \mathrm{~mL}, V_{\text {toluene }}=50 \mu \mathrm{L}$, under argon protection, $70^{\circ} \mathrm{C} ;{ }^{\mathrm{b}}$ Calculated from ${ }^{1} \mathrm{H}$ NMR of the raw experimental samples by comparing the integration of one vinyl protons of remaining monomer to the integration of initial monomer with toluene as internal standard; ${ }^{c}$ Determined by GPC with polystyrene as standards.

\section{Results and Discussion}

\subsection{Copolymerization of St and MSM}

Maleimide is a well-known electron deficient monomer, which has showed poor homopolymerization ability and has favored copolymerization with an electron-rich monomer. Herein, the selenide substituted maleimide, MSM, was copolymerized with styrene. RAFT polymerization was used for the aim of synthesis polymers with controlled molecular weight along with narrow molecular weight distribution. The polymerization results under different molar ratios of St to MSM were summarized in Table 1. As shown in Table 1, copolymerization of St and MSM could be carried out under RAFT polymerization using CPDN as the RAFT agent and AIBN as the initiator at $70{ }^{\circ} \mathrm{C}$. Polymers with narrow molecular weight distribution could be obtained. However, the molecular weight distribution $(\nexists)$ of the final copolymer increased with the decreasing of $[\mathrm{St}]_{0} /[\mathrm{MSM}]_{0}$ molar ratio, which may due to the reactivity of selenide with radical [30]. Furthermore, in case of no comonomer St (Table 1 Entry 5), no polymer was obtained even after $24 \mathrm{~h}$ of polymerization time, indicating that MSM is difficult to homopolymerize. 
To deeply understand the RAFT copolymerization behavior of St and MSM, the polymerization kinetics with different molar ratios were investigated. The results were showed in Figure 1. The results showed that all the polymerization kinetics conveyed linear plots. Such results indicated that the propagation radical concentration remained approximately constant during the polymerization period. The "living" / controlled feature can also be manifested by other results. Figure S5 (number-average molecular weight and molecular weight distribution $(\bigoplus)$ vary with the overall monomer conversion) showed good linear relationships between molecular weight and overall monomer conversion. The GPC curves of the obtained polymers at different feeding ratios (Figure S6) exhibited unimodal profiles in all cases, confirming that the resulting polymers are generated by the copolymerization of MSM and St, rather than being a mixture of two homopolymers. It could be observed that, in general, the consumption rate of MSM increased with the increase of $[S t]_{0} /[\mathrm{MSM}]_{0}$ molar ratio.

(a) $[\mathrm{St}]_{0} /[\mathrm{MSM}]_{0}=200 / 6$

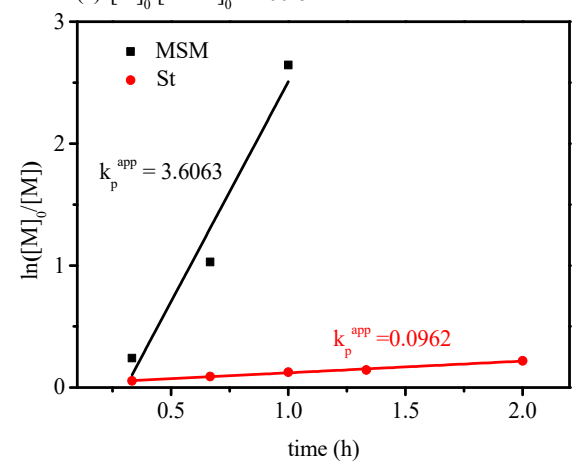

(c) $[\mathrm{St}]_{0} /[\mathrm{MSM}]_{0}=200 / 60$

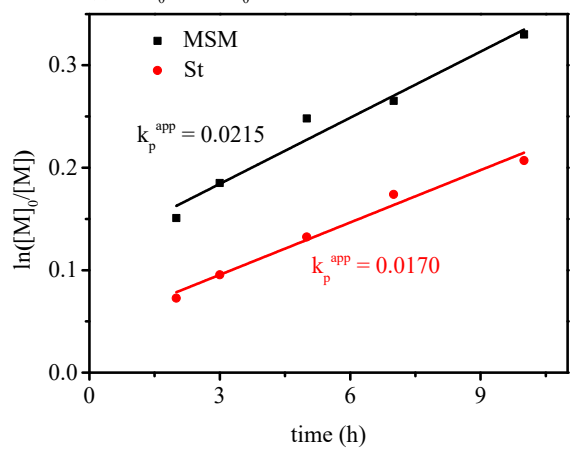

(b) $[\mathrm{St}]_{0} /[\mathrm{MSM}]_{0}=200 / 20$

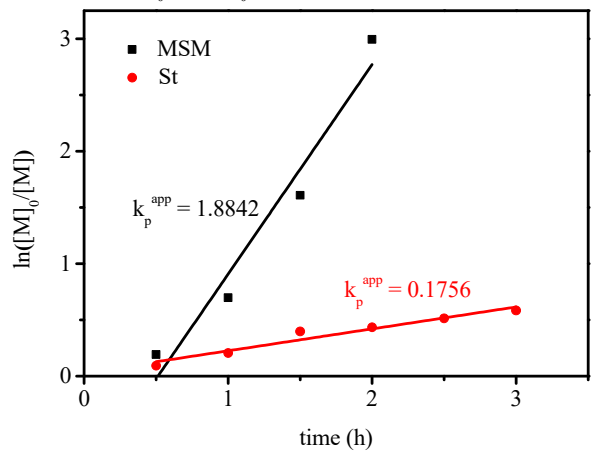

(d) $[\mathrm{St}]_{0} /[\mathrm{MSM}]_{0}=200 / 200$

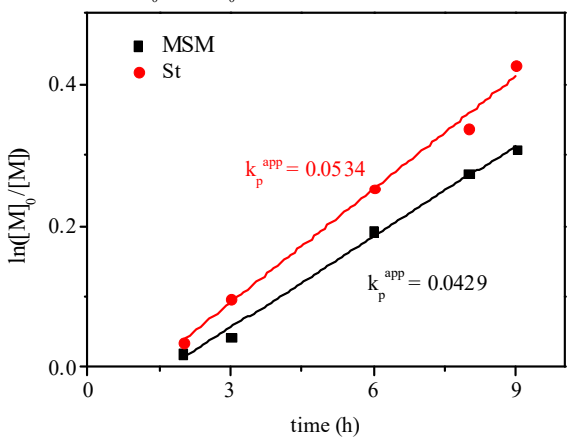

Figure 1. Kinetic plots of reversible addition-fragmentation chain transfer (RAFT) copolymerization of St and MSM with different molar ratios, (a) $[\mathrm{St}]_{0} /[\mathrm{MSM}]_{0}=200 / 6$; (b) $[\mathrm{St}]_{0} /[\mathrm{MSM}]_{0}=200 / 20$; (c) $[\mathrm{St}]_{0} /[\mathrm{MSM}]_{0}=200 / 60 ;(\mathrm{d})[\mathrm{St}]_{0} /[\mathrm{MSM}]_{0}=200 / 200, V_{\mathrm{St}}=1.0 \mathrm{~mL}, V_{\text {toluene }}=50 \mu \mathrm{L}$, temperature $70{ }^{\circ} \mathrm{C}$.

The structure of the polymer $\left([\mathrm{St}]_{0} /[\mathrm{MSM}]_{0} /[\mathrm{CPDN}]_{0} /[\mathrm{AIBN}]_{0}=200 / 200 / 2 / 1\right.$, precipitated in methanol, $M_{\mathrm{n}}=4600 \mathrm{~g} / \mathrm{mol}, \oslash=1.47$ ) was characterized by ${ }^{1} \mathrm{H}$ NMR, ${ }^{13} \mathrm{C}$ NMR, MALDI-TOF mass and FT-IR. From the Figure 2, the signals at about $\delta=2.50-3.40 \mathrm{ppm}$ could be ascribed to the protons adjacent to the nitrogen atom, protons from the fiveämembered ring, and protons from styrene monomeric unites adjacent to maleimide monomeric unites. The copolymer showed the signals at about 7.77-7.85 ppm $\left(2 \mathrm{H}\right.$, integration $\left.=I_{7.77-7.85}=2.0\right)$, which were ascribed to the protons at the chain end derived from CPDN. The signals at about $6.50-7.75 \mathrm{ppm}\left(10 \mathrm{H}\right.$, integration $\left.=I_{6.50-7.75}=216.0\right)$ were ascribed to the protons of benzyl from styrene monomeric unites and protons of phenyl-selenide groups. Based on the Figure 1d, the monomer ratio was 1:1 and the monomer conversion rates were close to each other. It can be assumed that the repeat units of St and MSM monomer are the same in the copolymer. Thus, the molecular weight $\left(M_{n, N M R}\right)$ can be calculated to be $4731 \mathrm{~g} / \mathrm{mol}$ by the equation $M_{n, \mathrm{NMR}}=(104+309) \times\left(I_{6.50-7.75} / 10\right)+271=(104+309) \times[(216.0 / 2) / 10]+271$, which was close to the value obtained by GPC $\left(M_{n, G P C}=4600 \mathrm{~g} / \mathrm{mol}\right)$. In ${ }^{13} \mathrm{C}$ NMR of the copolymer (Figure 6a), signals at $173.2 \mathrm{ppm}$ represented the $\mathrm{C}=\mathrm{O}$ groups in maleimide units. Figure 3 showed the MALDI-TOF mass 
spectrum of polymer $\left([\mathrm{St}]_{0} /[\mathrm{MSM}]_{0} /[\mathrm{CPDN}]_{0} /[\mathrm{AIBN}]_{0}=200 / 200 / 2 / 1\right.$, precipitated in methanol, $\left.M_{\mathrm{n}}=4600 \mathrm{~g} / \mathrm{mol}, \Xi=1.47\right)$. There were two kinds of peak serials with repeat units of $104.3 \mathrm{Da}$ and $153.9 \mathrm{Da}$, which could be ascribed to the MW of St and MSM respectively. The determined value of 1082.4 Da was matched the theoretical value of $1083.4 \mathrm{Da}$, which was corresponded to the polymer structure containing 4 St units and 3 MSM units after the elimination of CPDN fragment at the chain end of copolymer during MALDI-TOF mass testing. Loss of the selenium-containing fragment was attributed to a weak selenium-carbon bond cleavage and removal from the copolymer during MALDI-TOF mass testing [31]. In addition, the copolymer was analyzed by FT-IR spectrum (Figure S7) which showed characteristic adsorption peaks according to carbon-oxygen double bond at $1690 \mathrm{~cm}^{-1}$. The UV-vis spectrum of copolymer $\left([\mathrm{St}]_{0} /[\mathrm{MSM}]_{0} /[\mathrm{CPDN}]_{0} /[\mathrm{AIBN}]_{0}=200 / 200 / 2 / 1\right.$, precipitated in methanol, $M_{\mathrm{n}}=4600 \mathrm{~g} / \mathrm{mol}, Ð=1.47$ ) before oxidation showed weak adsorption peak at around 310 $\mathrm{nm}$, which can be attributed the adsorption of selenide moiety (Figure S8a). Such an adsorption peak disappeared in the UV-vis spectrum of copolymer after the oxidation $\left(M_{\mathrm{n}}=2300 \mathrm{~g} / \mathrm{mol}, Ð=1.43\right)$ (Figure S8b) verified the elimination of selenium phenyl groups. Therefore, the above data confirmed that the selenium-containing monomer MSM was successfully copolymerized with St and got a controlled copolymer.

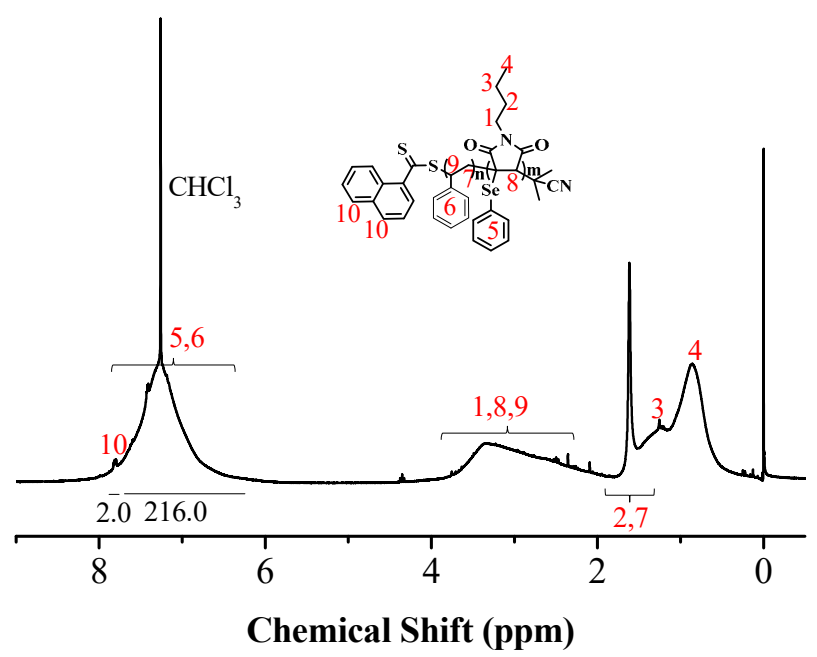

Figure 2. ${ }^{1} \mathrm{H}$ NMR spectrum of the RAFT copolymer in $\mathrm{CDCl}_{3}$.



Figure 3. Expanded MALDI-TOF mass spectrum of the RAFT copolymer by using Ag salt as the cationization agent and a DCTB matrix. 


\subsection{Oxidization of Copolymer}

The oxidative elimination of selenide moieties is one of the well-known reactions for selenium-containing compounds $[32,33]$. Herein, the obtained copolymer $\left([\mathrm{St}]_{0} /[\mathrm{MSM}]_{0} /[\mathrm{CPDN}]_{0} /\right.$ $[\text { AIBN] }]_{0}=200 / 200 / 2 / 1$, precipitated in methanol, $M_{\mathrm{n}}=4600 \mathrm{~g} / \mathrm{mol}, Ð=1.47$ ) was treated with hydrogen peroxide $\left(\mathrm{H}_{2} \mathrm{O}_{2}, 30 \%\right)$. The possible reaction was showed as Scheme 1. The structure of copolymer before and after the oxidization was characterized by GPC (Figure 4). It showed that the molecular weight of copolymer was decreased from 4600 to $2300 \mathrm{~g} / \mathrm{mol}$ after oxidization. Such a molecular weight decrease of the copolymer could be ascribed to the cleavage of the weak selenium-carbon bond. The structure of the oxidized copolymer was investigated by ${ }^{1} \mathrm{H}$ NMR spectrum as showed in Figure 5. In Figure 5, the oxidized copolymer showed the signals at about 4.80-5.80 ppm, which were ascribed to the protons from $\mathrm{C}=\mathrm{C}$ double bonds. The signals at about $7.77-7.85 \mathrm{ppm}\left(2 \mathrm{H}\right.$, integration $\left.=I_{7.77-7.85}=2.0\right)$, which were ascribed to the protons at the chain end derived from CPDN, the signals at about 6.20-7.75 ppm (integration $=I_{6.20-7.75}=164.0$ ) were ascribed to the protons of benzyl from repeat unites. Thus, combined with the ${ }^{1} \mathrm{H}$ NMR of copolymer before oxidization, the oxidization yield can be calculated to be $48 \%$ by the equation oxidization yield $=[(216.0 / 2-164.0 / 2)) / 5] /[(216.0 / 2) / 10]$. Such structure evolution also can be illustrated from the ${ }^{13} \mathrm{C}$ NMR in Figure $6 \mathrm{~b}$. The signals for the $\mathrm{C}=\mathrm{O}$ groups in the maleimide repeat unit shifted from 173.2 to $168.6 \mathrm{ppm}$ due to the formation of electron rich carbon-carbon double bond adjacent to $\mathrm{C}=\mathrm{O}$ after oxidation. However, the reaction efficiency of such a reaction in the current case was lower than those found in the literature $[33,34]$. However, the current results clearly demonstrated that the phenylselenide substitution could be partial oxidative cleavage from maleimide by $30 \% \mathrm{H}_{2} \mathrm{O}_{2}$, which resulted in the introducing of carbon-carbon double bonds in the backbone of copolymer.

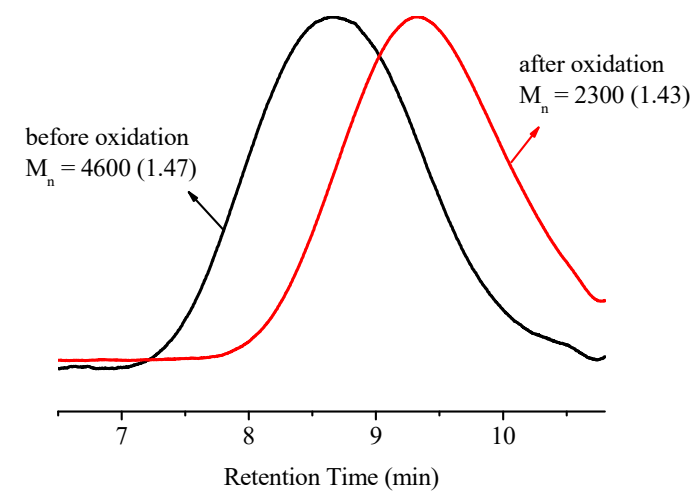

Figure 4. Gel permeation chromatograph (GPC) traces before and after oxidation using $30 \% \mathrm{H}_{2} \mathrm{O}_{2}$.

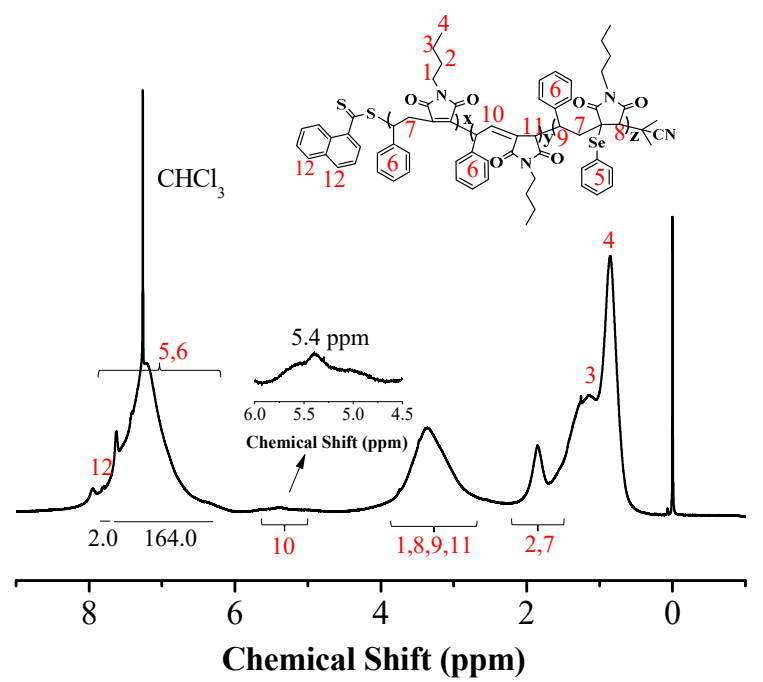

Figure 5. ${ }^{1} \mathrm{H}$ NMR spectrum of oxidized copolymer in $\mathrm{CDCl}_{3}$. 


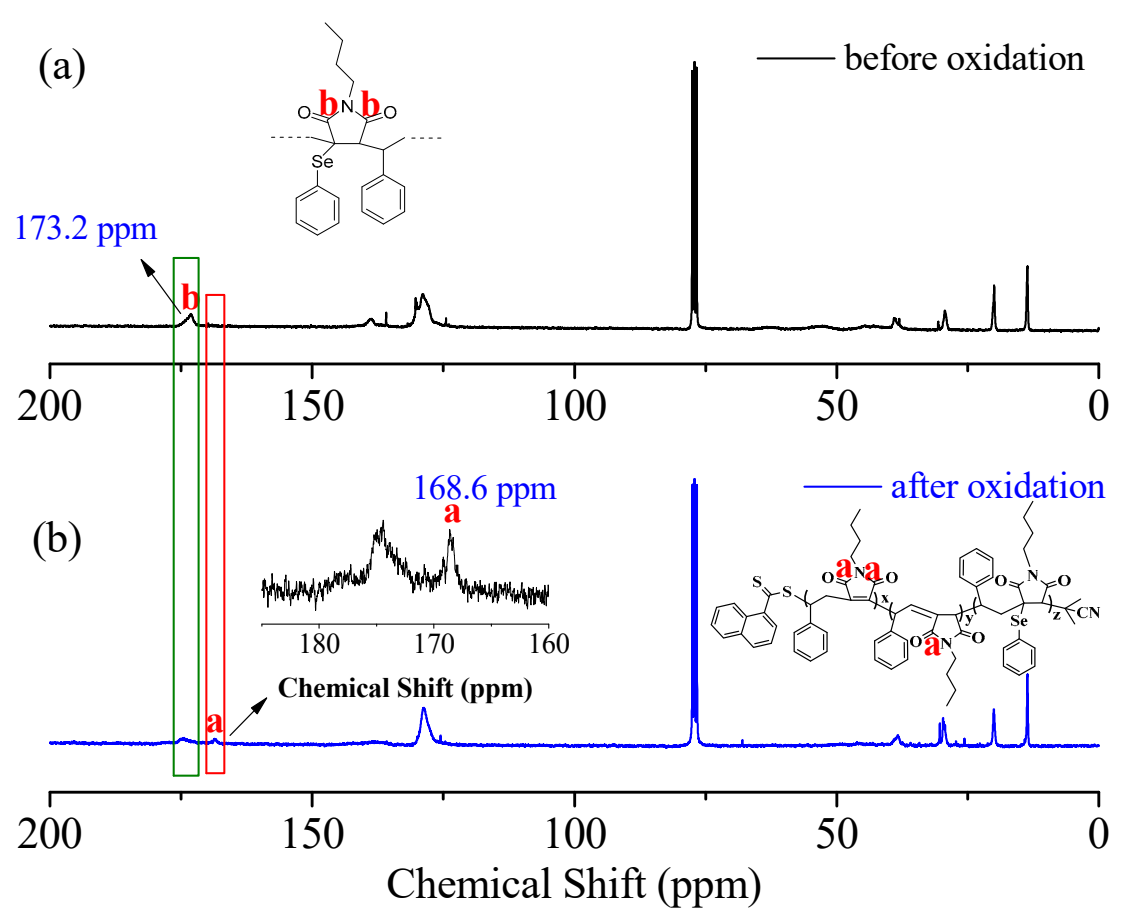

Figure $6 .{ }^{13} \mathrm{C}$ NMR spectrum of the oxidized copolymer.

\subsection{Thermal Properties of Selenium-Containing Copolymer and Oxidized Copolymer}

To determine the decomposition temperature of the copolymer before and after oxidization, TGA was tested under $\mathrm{N}_{2}$ atmosphere. The results were summarized in Figure 7 . The degradation temperature of copolymer before oxidization $\left([S t]_{0} /[\mathrm{MSM}]_{0} /[\mathrm{CPDN}]_{0} /[\mathrm{AIBN}]_{0}=200 / 200 / 2 / 1\right.$, precipitated in methanol, $M_{\mathrm{n}}=4600 \mathrm{~g} / \mathrm{mol}, \oslash=1.47$ ) was found to be $208^{\circ} \mathrm{C}$, causing the elimination of phenyl-selenide groups. For oxidized copolymer, the first degradation step was found at around $130{ }^{\circ} \mathrm{C}$, and its maximum weight loss occurred at $215^{\circ} \mathrm{C}$ with a $5 \%$ total weight loss which could be assigned to the elimination of phenyl-selenide groups. This was expected because the copolymer without oxidization possesses thermal stability higher than its oxidized copolymer which has been reported to initiate even at room temperature and increase rapidly with temperature [35]. We employed DSC under $\mathrm{N}_{2}$ to examine the glass transition temperature $\left(T_{g}\right)$ of copolymer before and after the oxidation. The results were showed in Figure 8. It indicated that the $T_{g}$ of oxidized copolymer $\left(82{ }^{\circ} \mathrm{C}\right)$ was lower than that of copolymer before oxidization $\left(142^{\circ} \mathrm{C}\right)$, which is presumably due to the introduction of a flexible double bond in the main chain after elimination of selenium phenyl groups.

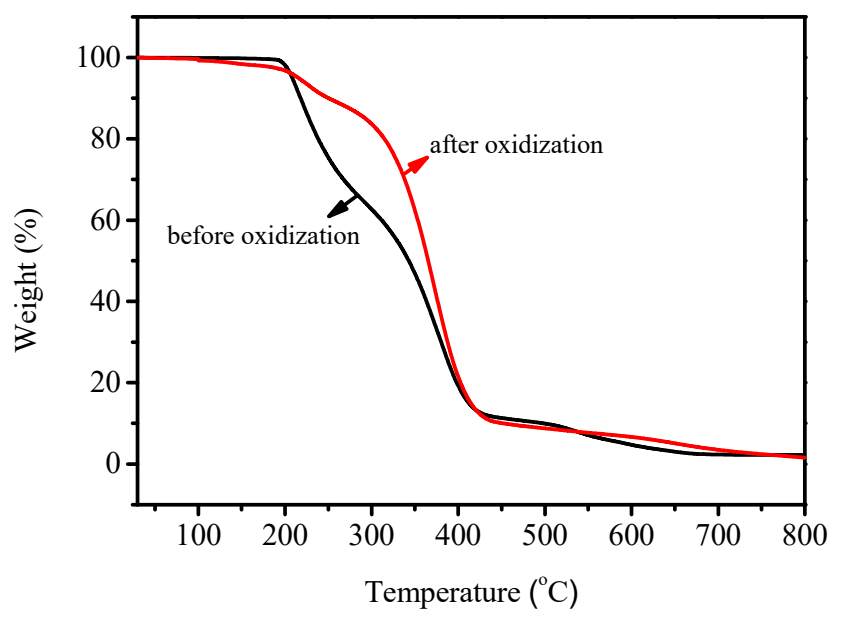

Figure 7. Thermogravimetric analysis (TGA) spectra of copolymers before and after oxidization. 

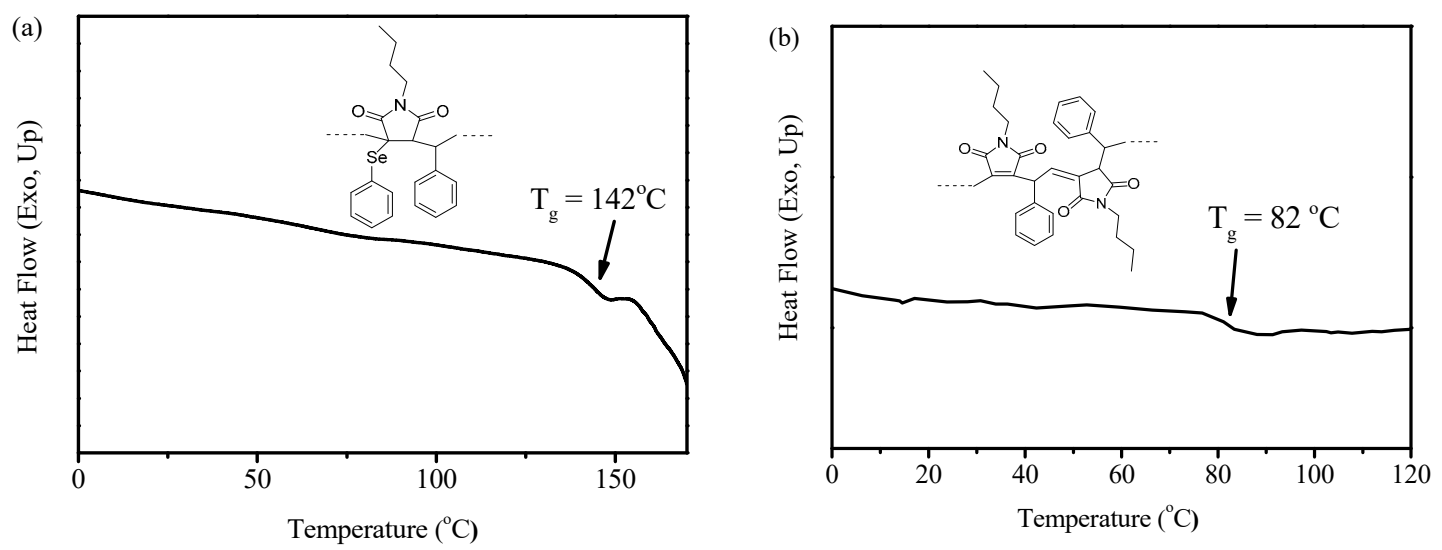

Figure 8. Differential scanning calorimetry (DSC) spectra of copolymers: (a) before oxidization (b) after oxidization.

\subsection{Photoluminescence Investigation}

It was demonstrated in the literature that maleimide with difference substitution showed interesting photoluminescence (PL) behavior. Thus, the photoluminescence behavior of copolymer $\left([\mathrm{St}]_{0} /[\mathrm{MSM}]_{0} /[\mathrm{CPDN}]_{0} /[\mathrm{AIBN}]_{0}=200 / 200 / 2 / 1\right.$, precipitated in methanol, $M_{\mathrm{n}}=4600 \mathrm{~g} / \mathrm{mol}$, $Ð=1.47)$ and its oxidized product $\left(M_{n}=2300 \mathrm{~g} / \mathrm{mol}, Ð=1.43\right)$ was investigated in solution and solid state. In THF, the copolymers before and after oxidization had excitation maxima at $410 \mathrm{~nm}$ and $370 \mathrm{~nm}$ respectively, see Figure S9. Figure 9 showed PL spectra of copolymer before and after oxidation in THF with different concentration. It showed that the PL behavior of copolymer in solution could be changed before and after the oxidation. The polymer before oxidation showed PL emission maximum at $510 \mathrm{~nm}$ with exciting wavelength of $410 \mathrm{~nm}$. The PL emission maximum shifted to $460 \mathrm{~nm}$ after oxidation with exciting wavelength of $370 \mathrm{~nm}$ due to the elimination of phenyl selenide. Furthermore, the PL emission enhancement with concentration was found in both of copolymers before and after the oxidation, which may be due to the aggregation of carbonyl groups in maleimide repeat units [36]. It was clear that such enhancement with concentration was more sensitive in case of copolymer after oxidation, both with or without the internal heavy atom effects of selenium atoms [37,38]. Such an effect was more noticeable at solid state. In Figure 10, with excitation at $370 \mathrm{~nm}$, the spectrum of oxidized copolymer at solid state featured strong emission peaks at $460 \mathrm{~nm}$. In contrast, the spectrum of copolymer without oxidization at solid state featured hardly any signal because of the impact from selenium.
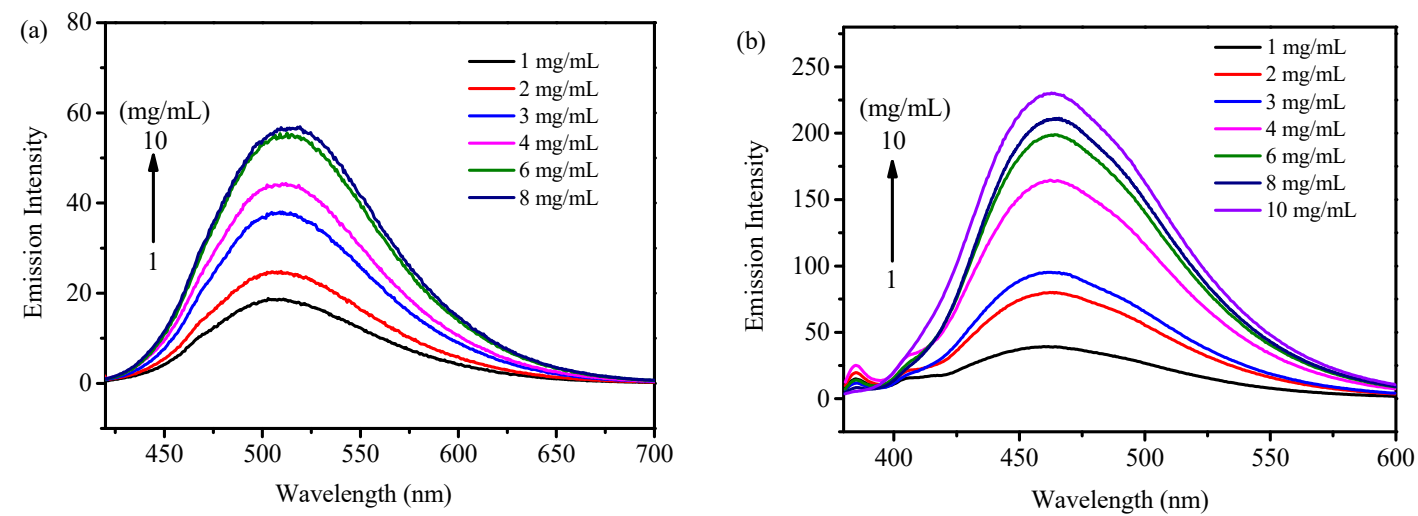

Figure 9. Photoluminescence (PL) spectra in THF at different concentrations (a) copolymer before oxidization, excited at $410 \mathrm{~nm}$; (b) oxidized copolymer, excited at $370 \mathrm{~nm}$. 


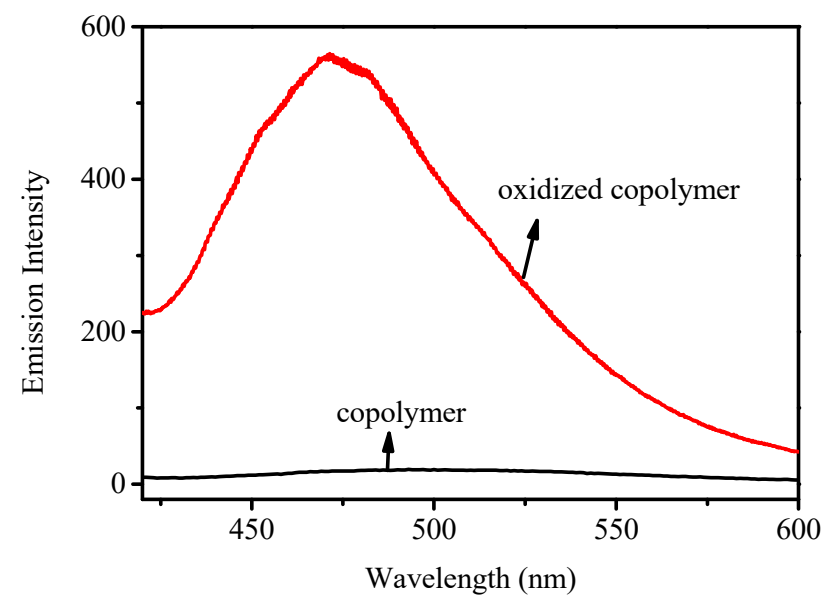

Figure 10. PL spectra of copolymer and oxidized copolymer at solid state, excited at $370 \mathrm{~nm}$.

\section{Conclusions}

The novel selenium-containing maleimide monomer MSM was successfully copolymerized with St through RAFT copolymerization at $70{ }^{\circ} \mathrm{C}$ using CPDN as the chain transfer agent and AIBN as the initiator. The feature of the controlled copolymerization was proven by the linear kinetic plots, controlled molecular weight and narrow molecular weight distribution of the copolymer. The structure of the obtained copolymer could be modified by eliminating phenylselenide under oxidative condition. This strategy provides a new method to prepare copolymers with selenide functional groups available for carbon-carbon double bonds formation in the backbone of a copolymer. By such structural modification, the thermal stability and PL emission property could be adjusted, e.g., improved thermal stability and enhanced PL emission intensity with concentration.

Supplementary Materials: The following are available online at www.mdpi.com/2073-4360/10/3/321/s1, NMR spectra, GPC curves, FT-IR spectrum, and UV-vis spectra of polymers.

Acknowledgments: This work was supported by the National Natural Science Foundation of China (Nos. 21302132, and 21374067), Joint research project of Jiangsu Province (BY2016051-01), the Priority Academic Program Development of Jiangsu Higher Education Institutions, and the Suzhou Key Lab of Macromolecular Design and Precision Synthesis.

Author Contributions: Jian Zhu and Xiangqiang Pan conceived and designed the experiments; Qian Liu performed the experiments and analyzed the data; Na Li analyzed the data; Xinghua Lv contributed analysis tools; Xiulin Zhu provided consulting during the paper preparation.

Conflicts of Interest: The authors declare no conflict of interest. The founding sponsors had no role in the design of the study; in the collection, analyses, or interpretation of data; in the writing of the manuscript, and in the decision to publish the results.

\section{References}

1. Ma, N.; Li, Y.; Xu, H.; Wang, Z.; Zhang, X. Dual Redox Responsive Assemblies Formed from Diselenide Block Copolymers. J. Am. Chem. Soc. 2010, 132, 442-443. [CrossRef] [PubMed]

2. Xu, H.; Cao, W.; Zhang, X. Selenium-Containing Polymers: Promising Biomaterials for Controlled Release and Enzyme Mimics. Acc. Chem. Res. 2013, 46, 1647-1658. [CrossRef] [PubMed]

3. Sarma, B.K.; Mugesh, G. Glutathione Peroxidase (GPx)-like Antioxidant Activity of the Organoselenium Drug Ebselen: Unexpected Complications with Thiol Exchange Reactions. J. Am. Chem. Soc. 2005, 127, 11477-11485. [CrossRef] [PubMed]

4. Nascimento, V.; Alberto, E.E.; Tondo, D.W.; Dambrowski, D.; Detty, M.R.; Nome, F.; Braga, A.L. GPx-Like Activity of Selenides and Selenoxides: Experimental Evidence for the Involvement of Hydroxy Perhydroxy Selenane as the Active Species. J. Am. Chem. Soc. 2012, 134, 138-141. [CrossRef] [PubMed] 
5. Selvakumar, K.; Shah, P.; Singh, H.B.; Butcher, R.J. Synthesis, Structure, and Glutathione Peroxidase-Like Activity of Amino Acid Containing Ebselen Analogues and Diaryl Diselenides. Chem. Eur. J. 2011, 17, 12741-12755. [CrossRef] [PubMed]

6. Ren, H.; Wu, Y.; Ma, N.; Xu, H.; Zhang, X. Side-chain selenium-containing amphiphilic block copolymers: Redox-controlled self-assembly and disassembly. Soft Matter 2012, 8, 1460-1466. [CrossRef]

7. Manjare, S.T.; Kim, Y.; Churchill, D.G. Selenium- and Tellurium-Containing Fluorescent Molecular Probes for the Detection of Biologically Important Analytes. Acc. Chem. Res. 2014, 47, 2985-2998. [CrossRef] [PubMed]

8. Manjare, S.T.; Kim, S.; Heo, W.D.; Churchill, D.G. Selective and Sensitive Superoxide Detection with a New Diselenide-Based Molecular Probe in Living Breast Cancer Cells. Org. Lett. 2014, 16, 410-412. [CrossRef] [PubMed]

9. Lu, W.; An, X.; Zhu, J.; Zhou, N.; Zhang, Z.; Pan, X.; Zhu, X. From seleno-mediated radical polymerization to seleno-containing branched polymers and dynamic hydrogel. RSC Adv. 2017, 7, 9773-9779. [CrossRef]

10. Kwon, T.S.; Kumazawa, S.; Yokoi, T.; Kondo, S.; Kunisada, H.; Yuki, Y. Living Radical Polymerization of Styrene with Diphenyl Diselenide as a Photoiniferter. Synthesis of Polystyrene with Carbon-Carbon Double Bonds at Both Chain Ends. J. Macromol. Sci. Part A Pure Appl. Chem. 1997, 34, 1553-1567. [CrossRef]

11. Tang, E.; Zhao, Y.; Li, W.; Wang, W.; Zhang, M.; Dai, X. Catalytic Selenium-Promoted Intermolecular Friedel-Crafts Alkylation with Simple Alkenes. Org. Lett. 2016, 18, 912-915. [CrossRef] [PubMed]

12. Robin, M.P.; Wilson, P.; Mabire, A.B.; Kiviaho, J.K.; Raymond, J.E.; Haddleton, D.M.; O’Reilly, R.K. Conjugation-Induced Fluorescent Labeling of Proteins and Polymers Using Dithiomaleimides. J. Am. Chem. Soc. 2013, 135, 2875-2878. [CrossRef] [PubMed]

13. Mabire, A.B.; Robin, M.P.; Quan, W.-D.; Willcock, H.; Stavros, V.G.; O’Reilly, R.K. Aminomaleimide fluorophores: A simple functional group with bright, solvent dependent emission. Chem. Commun. 2015, 51, 9733-9736. [CrossRef] [PubMed]

14. Dana, S.; Mandal, A.; Sahoo, H.; Baidya, M. Ru(II)-Catalyzed C-H Functionalization on Maleimides with Electrophiles: A Demonstration of Umpolung Strategy. Org. Lett. 2017, 19, 1902-1905. [CrossRef] [PubMed]

15. Tang, Z.; Wilson, P.; Kempe, K.; Chen, H.; Haddleton, D.M. Reversible Regulation of Thermoresponsive Property of Dithiomaleimide-Containing Copolymers via Sequential Thiol Exchange Reactions. ACS Macro Lett. 2016, 5, 709-713. [CrossRef]

16. Pucci, A.; Rausa, R.; Ciardelli, F. Aggregation-Induced Luminescence of Polyisobutene Succinic Anhydrides and Imides. Macromol. Chem. Phys. 2008, 209, 900-906. [CrossRef]

17. Chen, Y.; Spiering, A.J.H.; Karthikeyan, S.; Peters, G.W.M.; Meijer, E.W.; Sijbesma, R.P. Mechanically induced chemiluminescence from polymers incorporating a 1,2-dioxetane unit in the main chain. Nat. Chem. 2012, 4, 559-562. [CrossRef] [PubMed]

18. Qin, A.; Lam, J.W.Y.; Tang, B.Z. Luminogenic polymers with aggregation-induced emission characteristics. Prog. Polym. Sci. 2012, 37, 182-209. [CrossRef]

19. Mohamed, G.M.; Jheng, Y.-R.; Yeh, S.-L.; Chen, T.; Kuo, S.-W. Unusual Emission of Polystyrene-Based Alternating Copolymers Incorporating Aminobutyl Maleimide Fluorophore-Containing Polyhedral Oligomeric Silsesquioxane Nanoparticles. Polymers 2017, 9, 103. [CrossRef]

20. Zeng, J.; Zhu, J.; Zhang, Z.; Pan, X.; Zhang, W.; Cheng, Z.; Zhu, X. New selenium-based iniferter agent for living free radical polymerization of styrene under UV irradiation. J. Polym. Sci. Part A Polym. Chem. 2012, 50, 2211-2218. [CrossRef]

21. Zeng, J.; Zhu, J.; Pan, X.; Zhang, Z.; Zhou, N.; Cheng, Z.; Zhang, W.; Zhu, X. Organoselenium compounds: Development of a universal "living" free radical polymerization mediator. Polym. Chem. 2013, 4, 3453-3457. [CrossRef]

22. Okamoto, Y.; Chellappa, K.L.; Homsany, R. Reactions of alkyl phenyl selenide with benzoyl peroxide. J. Org. Chem. 1973, 38, 3172-3175. [CrossRef]

23. Lyons, J.E.; Schiesser, C.H.; Sutej, K. Free-radical homolytic substitution at selenium: An efficient method for the preparation of selenophenes. J. Org. Chem. 1993, 58, 5632-5638. [CrossRef]

24. Ando, T.; Kwon, T.S.; Kitagawa, A.; Tanemura, T.; Kondo, S.; Kunisada, H.; Yuki, Y. Synthesis and free radical polymerization of p-methylseleno- and p-phenylselenostyrenes. Macromol. Chem. Phys. 1996, 197, 2803-2810. [CrossRef]

25. Lu, W.; Pan, X.; Zhang, Z.; Zhu, J.; Zhou, N.; Zhu, X. A degradable cross-linked polymer containing dynamic covalent selenide bond. Polym. Chem. 2017, 8, 3874-3880. [CrossRef] 
26. Jiang, M.; Yang, H.; Fu, H. Visible-Light Photoredox Synthesis of Chiral $\alpha$-Selenoamino Acids. Org. Lett. 2016, 18, 1968-1971. [CrossRef] [PubMed]

27. Harihara Subramanian, S.; Prakash Babu, R.; Dhamodharan, R. Ambient Temperature Polymerization of Styrene by Single Electron Transfer Initiation, Followed by Reversible Addition Fragmentation Chain Transfer Control. Macromolecules 2008, 41, 262-265. [CrossRef]

28. Zhang, Z.; Wang, W.; Xia, H.; Zhu, J.; Zhang, W.; Zhu, X. Single-Electron Transfer Living Radical Polymerization (SET-LRP) of Methyl Methacrylate (MMA) with a Typical RAFT Agent as an Initiator. Macromolecules 2009, 42, 7360-7366. [CrossRef]

29. Nathani, R.I.; Chudasama, V.; Ryan, C.P.; Moody, P.R.; Morgan, R.E.; Fitzmaurice, R.J.; Smith, M.E.B.; Baker, J.R.; Caddick, S. Reversible protein affinity-labelling using bromomaleimide-based reagents. Org. Biomol. Chem. 2013, 11, 2408-2411. [CrossRef] [PubMed]

30. Ding, C.; Fan, C.; Jiang, G.; Zhang, J.; Li, X.; Li, N.; Pan, X.; Zhang, Z.; Zhang, W.; Zhu, J.; Zhu, X. Diselenide mediated controlled radical polymerization under visible light irradiation: Mechanism investigation and [small alpha],[small omega]-ditelechelic polymers. Polym. Chem. 2015, 6, 6416-6423. [CrossRef]

31. Ladavière, C.; Lacroix-Desmazes, P.; Delolme, F. First Systematic MALDI/ESI Mass Spectrometry Comparison to Characterize Polystyrene Synthesized by Different Controlled Radical Polymerizations. Macromolecules 2009, 42, 70-84. [CrossRef]

32. Liotta, D. New organoselenium methodology. Acc. Chem. Res. 1984, 17, 28-34. [CrossRef]

33. Vasil'ev, A.; Engman, L. Novel Preparation of $\alpha, \beta$-Unsaturated Aldehydes. Benzeneselenolate Promotes Elimination of $\mathrm{HBr}$ from $\alpha$-Bromoacetals. J. Org. Chem. 2000, 65, 2151-2162. [CrossRef] [PubMed]

34. Gautier, A.; Garipova, G.; Deléens, R.; Piettre, S.R. Carbenoid-mediated elimination of sulfides and selenides. A mild and efficient method for introducing $\alpha, \beta$-double bonds to electron-withdrawing substituents. Tetrahedron Lett. 2002, 43, 4959-4962. [CrossRef]

35. Leung, L.M.; Tan, K.H. Synthesis and electrical properties of polyacetylene copolymers from poly(phenyl vinyl sulfoxide) and its oxidized products. Macromolecules 1993, 26, 4426-4436. [CrossRef]

36. Lu, H.; Feng, L.; Li, S.; Zhang, J.; Lu, H.; Feng, S. Unexpected Strong Blue Photoluminescence Produced from the Aggregation of Unconventional Chromophores in Novel Siloxane-Poly(amidoamine) Dendrimers. Macromolecules 2015, 48, 476-482. [CrossRef]

37. Detty, M.R.; Prasad, P.N.; Donnelly, D.J.; Ohulchanskyy, T.; Gibson, S.L.; Hilf, R. Synthesis, properties, and photodynamic properties in vitro of heavy-chalcogen analogues of tetramethylrosamine. Bioorg. Med. Chem. 2004, 12, 2537-2544. [CrossRef] [PubMed]

38. Piao, W.; Hanaoka, K.; Fujisawa, T.; Takeuchi, S.; Komatsu, T.; Ueno, T.; Terai, T.; Tahara, T.; Nagano, T.; Urano, Y. Development of an Azo-Based Photosensitizer Activated under Mild Hypoxia for Photodynamic Therapy. J. Am. Chem. Soc. 2017, 139, 13713-13719. [CrossRef] [PubMed] 